\title{
Práticas de Letramento no contexto do UCA
}

\author{
Silvia de Oliveira Kist, Marie Jane Soares Carvalho
}

\author{
Programa de Pós-Graduação em Educação - Universidade Federal do Rio Grande do \\ Sul (UFRGS) \\ Porto Alegre - RS - Brazil \\ \{silvia.kist, marie.jane\}@ufrgs.br
}

\begin{abstract}
This paper discusses the factors that impact on literacy in the context of the project One Laptop per Student (UCA). We conducted a case study in a class of $1^{\text {st }}$ year of primary school, part of the UCA project. We analyzed the literacy practices proposed by the teacher and students spontaneous literacy practices from the daily use of laptops connected to the internet. We concluded that for a culture of literacy arise in schools is necessary a tecnology systems ecology that acts as foundation: the usage of laptops in 1:1, connection to the internet and use of a virtual learning environment for communication and authorship.
\end{abstract}

Resumo. O presente artigo tem por objetivo discutir fatores que impactam sobre o letramento no contexto do projeto Um Computador por Aluno (UCA). Realizamos um estudo de caso em uma turma de $1^{o}$ ano do ensino fundamental, contemplada com o projeto UCA. Analisamos as práticas de letramento propostas pela professora e as práticas de letramento espontâneas a partir do uso cotidiano dos laptops conectados à internet. Concluímos que para o surgimento de uma cultura de letramento na escola é necessário que uma ecologia de sistemas a subsidie: o laptop na modalidade 1:1, a conexão com a internet e o uso de um ambiente virtual de comunicação e autoria.

\section{O estudo}

O ano de 2007 foi um marco para a abertura de novas possibilidades no campo da Informática na Educação brasileira que, até então, era dominada basicamente por experiências pedagógicas em laboratórios de informática.

$\mathrm{O}$ acesso à tecnologia computacional de baixo custo e os princípios do modelo 1:1, popularizados pela organização sem fins lucrativos One Laptop per child-OLPC, propunham novas formas de exploração com a tecnologia as quais, em conceito, abririam novos espaços para as práticas realizadas pelo aluno, independente das propostas do professor. O princípio de propriedade da máquina pela criança, proposto pela $O L P C$, trazia em seu conceito a ampliação do controle do aluno sobre os tempos e espaços da aprendizagem com a tecnologia. Da mesma forma, defendia a minimização da exigência sobre o professor em relação ao domínio a priori da tecnologia para "ensinar" os alunos, bem como, enfraquecia a sua responsabilidade como o único fator determinante ao sucesso ou fracasso do projeto.

Sabemos que o princípio de "propriedade do laptop pela criança" ainda não é consenso em todas as iniciativas do projeto brasileiro de Um Computador por aluno - 
UCA. Número de equipamentos insuficiente para todos os alunos, receio de danos, a legitimação do uso estritamente pedagógico, perdas e roubos são argumentos comuns entre muitos gestores para manterem as máquinas confinadas ao ambiente escolar, sem a posse ou autonomia de uso pelas crianças.

Nosso estudo diz respeito a uma das primeiras experiências do projeto UCA no país em que os princípios sistematizados pela $O L P C$ foram aplicados, no ano 2007. Isso é relevante, na medida em que a investigação surge da hipótese que a posse do laptop pela criança potencialmente criaria um ambiente mais favorável para o desenvolvimento do letramento e da fluência tecnológica, não restrito ao engajamento do professor com o projeto.

O contexto desse projeto na modalidade 1:1 permitiu aprofundarmos uma inquietação que tínhamos há bastante tempo em relação às dificuldades de aprendizagem da leitura e da escrita apresentadas por crianças de classe desfavorecida social e economicamente. Vislumbrávamos novas possibilidades de relação com a língua escrita através do uso de tecnologias digitais. Investigamos as práticas de leitura e de escrita de um grupo de crianças imersas em um cotidiano digital, viabilizado pelo projeto UCA, na modalidade 1:1, analisando suas implicações no processo de conceituação da língua escrita (Kist, 2009).

Esse artigo é um recorte dessa pesquisa e temos por objetivo discutir quais fatores impactam sobre o letramento no contexto do projeto um computador por aluno. Nos colocamos como questão: Quais são as possibilidades e condições necessárias para que o computador seja instrumento promotor de uma cultura de letramento?

Partimos para o estudo com a proposição teórica de que o uso do laptop no cotidiano criaria um ambiente propício, capaz de inscrever a criança no mundo letrado, superando a relação estritamente escolar com a escrita e proporcionando outra forma de inserção social. Os princípios de uso do laptop da $O L P C$, principalmente (1) a propriedade da criança e (2) a saturação, também compõe essa proposição a medida em que apontam para uma situação na qual a instituição escolar não será capaz de repetir o movimento do passado, quando assimilou o computador à sua lógica tradicional de funcionamento, "encerrando-os" em laboratórios (Papert, 1994).

\section{Definições Teóricas}

O conceito de letramento é recente e, portanto, não é consensual entre diferentes pesquisadores da área. Ferreiro (2003), por exemplo, defende uma semelhança entre alfabetização e o que se entende por letramento, questionando a necessidade desse último. No entanto, nosso estudo compartilha as ideias de Maraschin (1995) e Soares (2004) em relação à distinção entre esses dois conceitos considerando os estudos da primeira pesquisadora, quando analisa as práticas realizadas em algumas escolas que se centram exclusivamente no ensino do funcionamento e da mecânica da língua, esquecendo os seus usos reais.

Entendemos a Alfabetização como "processo ativo do sujeito para a compreensão da estrutura da língua e do funcionamento do código alfabético, bem como, da consciência fonêmica" (Kist, 2009, p.48). O conceito de letramento adotado

tem raízes naquele utilizado por Soares - "estado ou condição de quem exerce as práticas sociais de leitura e de escrita, de quem participa de eventos em que a escrita é parte integrante da interação entre pessoas e do processo de interpretação dessa interação" 
(Soares, 2002, p. 145), - mas dele difere em relação à concepção de estado ou condição, sendo entendido mais como um processo de desenvolvimento de um indivíduo ou grupo social ao exercer práticas sociais de leitura e de escrita e apropriar-se da sua função (Kist 2009, p.48)

Por último, entendemos que a conceituação da língua escrita é um processo fruto da ativação dos sistemas significação e dos sistemas lógicos do sujeito. Nesse sentido, é dependente desses dois outros processos: alfabetização (compreensão do funcionamento do código) e letramento (compreensão da função e a capacidade de uso da língua escrita).

As crianças de 6 anos, ao ingressarem à escola, estão vivenciando mais formalmente o processo de conceituação da língua escrita, embora saibamos que esse processo inicia muito previamente. Por isso, acreditamos que a ausência de uma cultura de letramento, ou seja, a ausência de interação simbólica envolvendo a língua escrita, de contato com portadores de texto e com práticas sociais de leitura e escrita no cotidiano são elementos contribuintes com a dificuldade das crianças em compreender a função da língua e, conseqüentemente, a aprendizagem do código.

\section{Caracterização dos sujeitos e do estudo}

Nosso estudo foi realizado em uma turma de 19 alunos de 6 anos de idade, do $1^{\circ}$ ano do ensino de 9 anos, de uma escola pública. A escola recebeu doação dos laptops XOs da $O L P C$ para realizar um dos primeiros pilotos 1:1 no mundo. Ela contava com conexão à Internet e dispunha de um ambiente virtual para uso exclusivo da comunidade escolar. Os professores da escola participavam da formação do grupo de pesquisas da universidade local. As crianças do $1^{\circ}$ ano utilizavam o laptop diariamente em função das propostas da professora ou de usos espontâneos na escola e em casa. O trabalho com projetos de aprendizagem, conforme Fagundes (1999), fazia parte das propostas da professora.

A presente pesquisa foi construída como um estudo de caso conforme Yin (2001), teve duração de 6 meses e contou com diversas fontes de evidências: testagens psicogenéticas de língua escrita no início e final da pesquisa, a partir de Ferreiro (1999), diários de campo dos pesquisadores, dados do ambiente virtual, dados de todas as produções realizadas pelos alunos e armazenados no histórico dos laptops XOs, além de entrevistas clínicas, vídeos e fotos.

Em relação ao nível de escrita, no início do estudo, havia sete alunos no nível inicial (Pré-silábico) usando letras aleatórias para escrever, quatro alunos no nível intermediário I (Silábico) usando uma letra para cada sílaba, dois no nível intermediário II (Silábico-alfabético) oscilando entre letras e sílabas e seis alunos no nível avançado (Alfabéticos), escrevendo com sílabas. Desses, oito alunos não compreendiam a função da língua escrita, seis compreendiam parcialmente e cinco compreendiam. No que diz respeito ao contato prévio com computador, oito alunos nunca haviam utilizado a máquina, três tinham computador em casa, mas não usavam e oito alunos já utilizavam computador.

O estudo foi dividido em duas unidades de análise: práticas propostas pelo professor e práticas espontâneas dos alunos, cada uma com seu eixo de categorias. Nesse artigo vamos centrar no eixo de categorias relativas ao letramento. Veja o quadro 1 abaixo: 


\section{Quadro 1. Categorias do eixo Letramento}

\begin{tabular}{|l|l|}
\hline $\begin{array}{l}\text { Práticas de letramento propostas pela professora com o } \\
\text { uso do laptop }\end{array}$ & $\begin{array}{l}\text { Práticas de letramento espontâneas dos alunos com o } \\
\text { uso do laptop }\end{array}$ \\
\hline Inclusão no mundo letrado & Participação em práticas de letramento no contexto digital \\
\hline A utilização da língua escrita para atingir um fim & A utilização da língua escrita para atingir um fim \\
\hline Exercício da autoria na escrita & Exercício da autoria na escrita \\
\hline Comunicação através da língua escrita & Comunicação através da língua escrita \\
\hline Estratégias para ler ou escrever & Estratégias para ler ou escrever \\
\hline
\end{tabular}

Discutiremos cada um dos eixos de análise e suas categorias na seção seguinte.

\section{Práticas de letramento propostas pela professora com o uso do laptop}

O objetivo dessa seção é analisar as práticas propostas pela professora que foram potencializadas com o uso do laptop no que se refere ao letramento. Cabe a ressalva feita por Ferreiro (1999, p. 31) de que "o método (enquanto ação específica do meio) pode ajudar ou frear, facilitar ou dificultar, porém não pode criar aprendizagem. A obtenção de conhecimento é resultado da própria atividade do sujeito". Dessa forma, os dados analisados são extratos das práticas realizadas pelos alunos desencadeadas pela proposta da professora.

\subsection{Inclusão no mundo virtual letrado}

Para incorporar a língua escrita ao cotidiano é necessário, além do domínio do código, a compreensão de sua função. Um dos fatores que contribuem com a compreensão da função da língua é estar incluído (como agente) em um mundo letrado (Soares, 2006).

Nas propostas da professora, uma das práticas possibilitadas pelo laptop, que suscita a entrada dos alunos de 6 anos de idade em um mundo virtual e letrado, no qual o sujeito é demandado a exercer práticas sociais de leitura e escrita, iniciou com o trabalho no ambiente virtual de aprendizagem - AMADIS (Bittencourt et al., 2006). A participação em um ambiente habitado por todos os escolares da instituição de ensino torna factível diferentes níveis de interação. Todos os alunos do $1^{\circ}$ ano tinham um nome de usuário e uma senha para acessar o ambiente virtual, bem como um perfil com foto, conforme Figura 1.

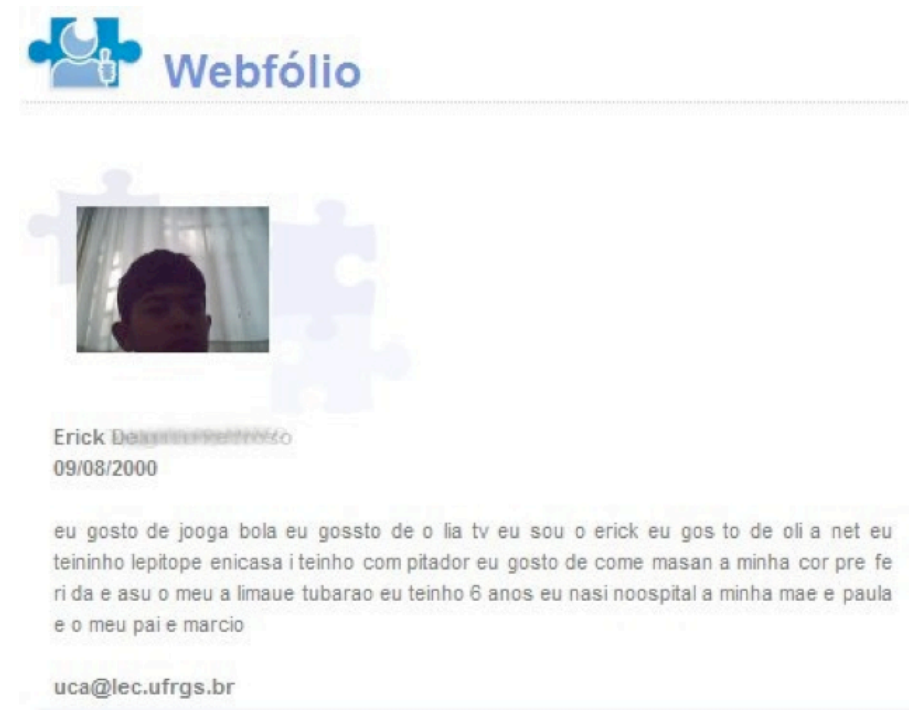

Figura 1 - Webfólio do aluno ER 
As propostas que envolviam o desenvolvimento dos projetos, proporcionaram a continuidade do trabalho de uso do ambiente, possibilitando às crianças fazer parte desse meio virtual baseado no código escrito. A professora desenvolveu com sua turma o Projeto chamado Curiosidade Premiada, inspirado na Metodologia de Projetos de Aprendizagem (Fagundes, 1999). Nessa prática os alunos puderam expressar suas curiosidades e escolher algumas questões para realizar uma investigação, como por exemplo: O que os golfinhos comem? Por que os tiranossauros não ficam banguelas? $\mathrm{O}$ que os leões fazem além de atacar e comer? Como o elefante bebe água? Por que os morcegos chupam sangue?

A sistemática de publicação no diário das descobertas sobre as questões dos projetos e das fotos, desenvolveu uma rotina de uso do ambiente, como pode ser observado nas Figuras 2 e 3, com o registro sobre diferentes temáticas dos projetos. Todos os projetos deveriam ser registrados no diário do AMADIS.

O tiranossauro fica banguela? - 09:10 16/10/2007

euacho que o tiranossauro fica banguela porque foi encontrado dente na terra. o trex fica banguela igual a outros animais.

Figura 2 - Registro no diário do aluno BA sobre o projeto: Por que os tiranossauros não ficam banguelas?

projetos - 09:55 31/10/2007

eu sou o cesar alves petracco eu to progetando porque os

e os leoins.

e mais a uca.

Figura 3 - Registro no diário do aluno CE sobre o projeto "Por que os tiranossauros não ficam banguelas?"

\subsection{A utilização da língua escrita para atingir um fim}

Constatamos que em todas as propostas que envolviam o uso do ambiente de aprendizagem AMADIS a escrita era utilizada para atingir um fim. Para ingressar nessa "grande casa que é o AMADIS (metáfora utilizada para que as crianças entendessem o que é o ambiente na web) era necessário o uso da língua, porque elas precisavam digitar o site e se identificar com nome e senha. Esses eram chamados de "chave de entrada da casa". Para registrar as descobertas dos projetos no seu "quarto" (ferramenta diário), a escrita se fazia necessária.

No trabalho com Projetos, independente do uso do ambiente, a escrita foi utilizada para buscar informações e imagens na Internet. Na prática de buscar imagem da Internet, não há a limitação para escrever somente palavras com sílabas simples, comuns às salas de aula de alfabetização. A curiosidade da criança e a pergunta do projeto guiaram o tipo de palavra a ser escrita; elas determinaram as letras, os sons, as palavras que foram aprendidas.

\subsection{Exercício da autoria na escrita}

Dentre as inúmeras práticas em que os alunos exerceram autoria sobre sua escrita, isto é, utilizaram a língua escrita com sentido para se expressar, destacamos a prática de salvar imagens da Internet para o projeto, alterando espontaneamente o nome original do 
arquivo. O aluno FA, ao salvar imagens da Internet, descobriu que podia modificar-lhes o nome. A prática de alterar o nome indica uma compreensão da função da língua e um exercício da função de autoria, porque é possível agir sobre o código e expressar significações próprias. Essa apropriação pode ser vista no extrato a seguir, em que o aluno atribui diferentes nomes para as imagens de elefante. Esse procedimento foi adotado por vários alunos, como ilustra a Figura 3.

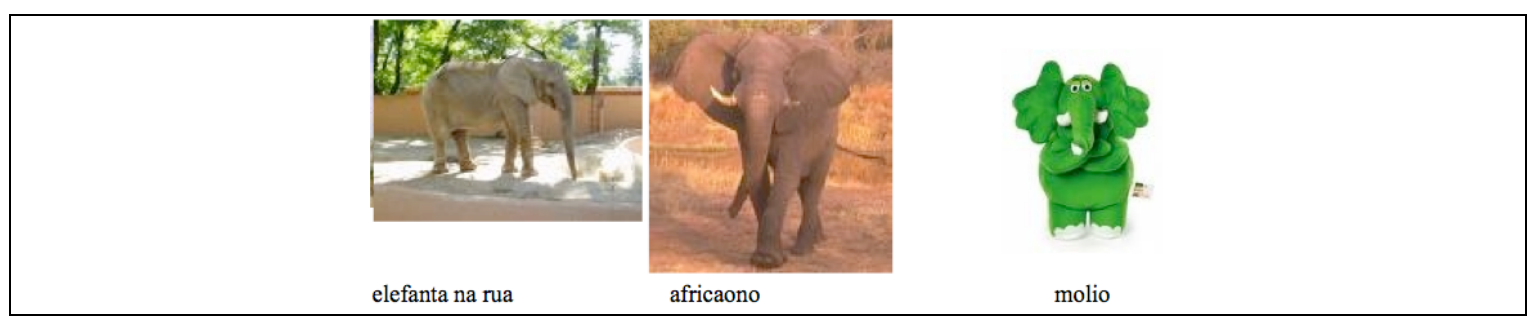

Figura 4 - Aluno FA cria novos nomes para as imagens ao salvar no seu laptop.

\subsection{Comunicação através da língua escrita}

A comunicação assíncrona em rede é um dos fatores que contribuem com a compreensão das funções da escrita. A ação da professora de enviar mensagens aos seus alunos dentro do ambiente virtual teve a intenção de promover a comunicação através do uso da língua escrita. O comentário aos posts do diário dá a garantia às crianças que sua escrita está sendo lida por interlocutores reais.

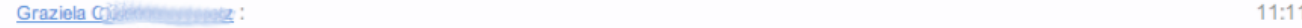

Meu querido William, é muito legal escrever esta mensagem. Tu és um aluno muito especial e inteligente. Quero ler o teu diário e 01/11/2007 saber tudo que estas aprendendo.Beijocas,Graziela.

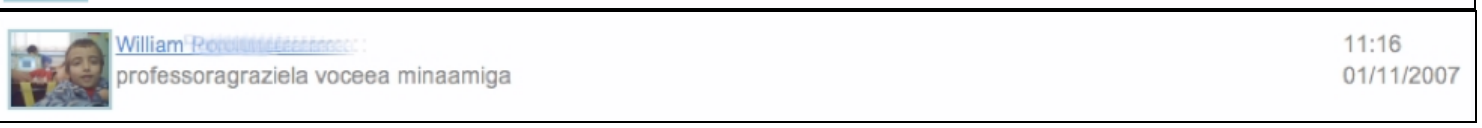

Figura 5 - Comunicação via comentários no diário entre a professora e o aluno

\subsection{Exploração de diferentes estratégias para ler ou escrever}

No processo de letramento, não há necessidade de domínio do código para o exercício/uso da língua escrita. O uso do computador, por permitir inúmeras manipulações simbólicas, potencializa o processo na medida em que possibilita a utilização de estratégias de leitura e escrita, sendo possível atingir um grau de letramento, sem dominar completamente o código. Nesse momento inicial de conceituação a língua escrita, mais importante do que escrever corretamente, é sentir-se seguro para escrever conforme sua hipótese, refletir sobre a função e funcionamento da língua, criando estratégias para escrever, mesmo que não convencionalmente. Nas figuras anteriores podemos observar as diferentes hipóteses de escrita dos alunos. Cabe destacar que mesmo os alunos que ainda não compreendiam a dinâmica da escrita usavam estratégias para participar no ambiente virtual: copiavam palavras dos cartazes, pediam ajuda aos colegas, escreviam letras aleatórias. 


\section{Práticas de letramento espontâneas dos alunos com o uso do laptop}

As práticas espontâneas de letramento fazem parte do processo pelo qual passam os indivíduos ao apropriarem-se da língua escrita e de seus usos sociais.

O princípio "propriedade do laptop pela criança” garante que a máquina esteja presente além do espaço escolar ou que, mesmo no espaço escolar, seja utilizada espontaneamente pela criança, sem a dependência de uma proposição da professora. Nessa unidade de análise, procuramos entender e diferenciar os usos que as crianças fazem da escrita (letramento) sem a proposição ou a intervenção da professora.

\subsection{Participação em Práticas de Letramento no Contexto Digital}

O uso do ambiente virtual AMADIS, iniciado com uma proposta da professora, tornouse progressivamente uma prática diária e espontânea no cotidiano de alguns alunos do $1^{\circ}$ ano. Eles manifestavam interesse em entrar no AMADIS, seja para ver o webfólio (perfil) dos colegas, seja para ler suas mensagens, mesmo quando a proposta de aula não envolvia o uso do ambiente. Observamos a emergência de uma cultura de letramento na sala de aula. Outra prática que indica o pertencimento a um determinado ambiente social letrado é quando as crianças criaram redes de relações, adicionando outros usuários como amigos. Alguns alunos restringiram-se a adicionar colegas da turma. Outros adicionaram professores, pesquisadores e alunos de outras turmas, ampliando sua rede de relações. Apenas uma aluna não adicionou amigos.

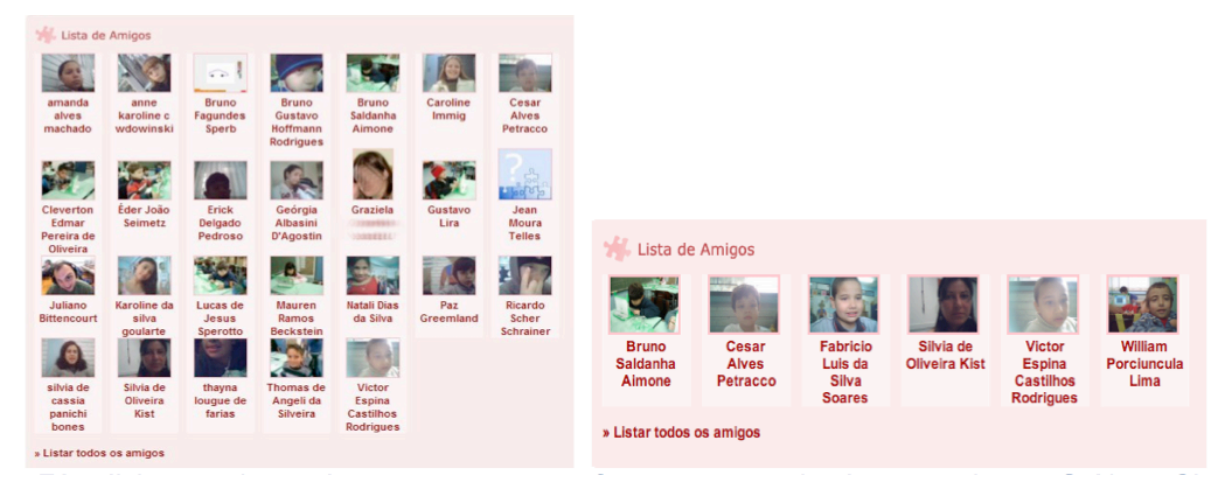

Figura 6 - Amigos do aluno FA (à esquerda) e amigos do aluno CL (à direita)

\subsection{A Utilização da Língua Escrita para Atingir um Fim}

Outro procedimento em que a língua escrita se fazia presente constituiu-se em localizar os colegas que estavam próximos pela rede mesh do laptop, através da identificação dos respectivos ícones do XO. Ao deixar o apontador do mouse sobre um XO, aparecia o nome do usuário correspondente ao ícone.

Para realizar a prática de entrar em sites de jogos, localizar sites ou imagens de interesse, a escrita foi condição sine qua non para a utilização da ferramenta. $O$ procedimento de entrar na Internet e salvar imagens foi trabalhado pela professora com as crianças para a busca das figuras dos animais dos projetos. No entanto, ele foi generalizado para a busca de outras imagens. Durante essa prática espontânea, aconteceram fatos que contribuíram para a construção da língua escrita, como a aprendizagem de "formas fixas", ou seja, palavras incorporadas pelo sujeito que serviram de modelos para pensar a escrita de outras palavras. 


\subsection{Exercício da Autoria na Escrita}

A prática de expressão escrita espontânea teve início com o aluno PA, ao escrever no diário do AMADIS sobre assuntos de seu interesse cf. Figura 7. Como o aluno tinha computador com Internet em casa, realizava tal ação durante a aula e também fora do espaço escolar. Os demais colegas tomaram conhecimento com PA sobre essa possibilidade e iniciaram a fazê-la. Capturavam imagem da Internet e inseriam-na no seu diário do AMADIS, ou somente escreviam no diário do AMADIS espontaneamente, independentemente da solicitação da professora e dos projetos de aula. PA escrevia sobre o que desejava, sobre coisas que achava interessante e de que gostava, sobre sua rotina, como lugares que visitou, horário em que acordou, seus filmes e brinquedos preferidos, fazendo uma interlocução com o leitor.

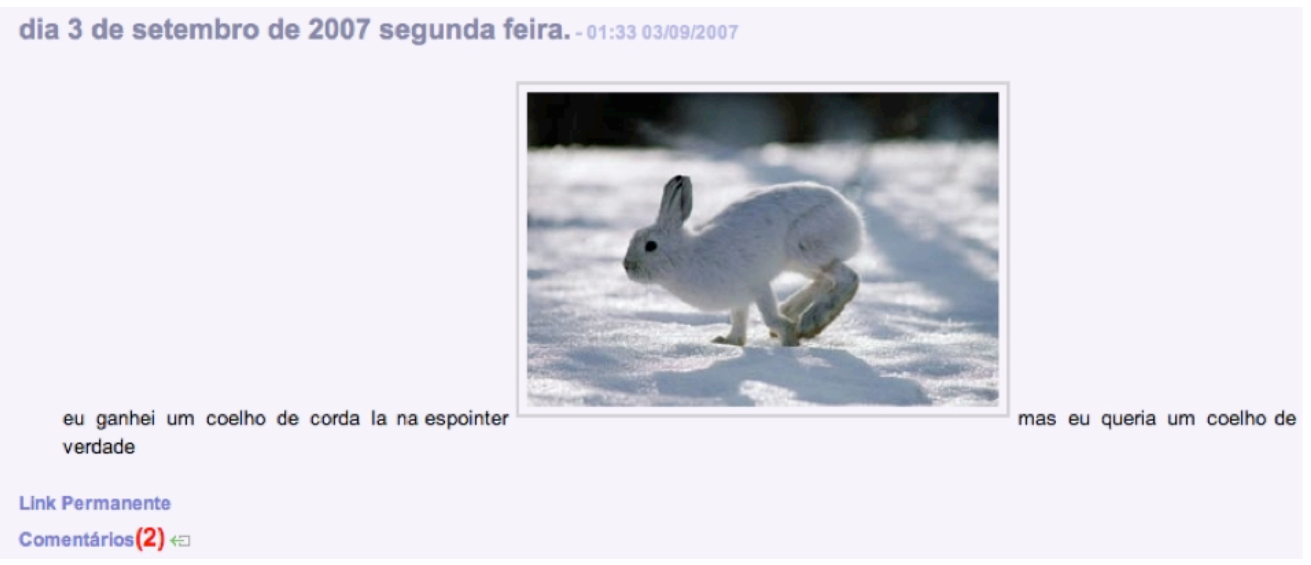

Figura 7 - Registro espontâneo do aluno PA no seu diário

\subsection{Comunicação através da Língua Escrita}

Paralelamente à apropriação do AMADIS e também da língua escrita, os alunos iniciaram a prática de fazer uso do recurso de envio de mensagem pelo AMADIS.

\begin{tabular}{|c|c|}
\hline $\begin{array}{ll}2 & \text { William } \\
\text { eusouoteuamigo }\end{array}$ & $\begin{array}{l}10: 48 \\
01 / 11 / 2007\end{array}$ \\
\hline Tla & $\begin{array}{l}10: 54 \\
01 / 11 / 2007\end{array}$ \\
\hline
\end{tabular}

\section{Figura 8 - WI adiciona um colega como amigo e envia uma mensagem lhe comunicando. Em menos de 6 minutos, o aluno ER lê a mensagem e a responde.}

\subsection{Estratégias para Ler ou Escrever}

Uma estratégia utilizada por várias crianças foi a de fotografar portadores de texto dentro e fora da sala de aula. VI, um usuário assíduo no AMADIS, utilizava a estratégia de copiar o nome dos colegas do cartaz exposto na sala de aula para que pudesse entrar em seus webfólios e adicioná-los como amigos. FA costumava copiar a palavra presente na imagem da capa dos cadernos como uma estratégia para buscar a imagem no Google. 


\section{Conclusões}

Em relação às propostas da professora, muitas geraram práticas referentes ao letramento, principalmente quando envolviam o trabalho por projetos e o uso do ambiente virtual. Nessas práticas, os alunos tiveram a oportunidade de utilizar a língua escrita com significado e não apenas como aprendizagem de uma técnica de codificação e decodificação.

O uso do ambiente virtual foi potencializador para as práticas de letramento, na medida em que possibilitava que as crianças nele inseridas exercessem práticas sociais de leitura e escrita e utilizassem a língua escrita para comunicar-se. No entanto, dentre as propostas da professora, o uso do ambiente virtual teve maior sentido a partir do trabalho por projetos. Quando os projetos eram executados, o ambiente era utilizado para a expressão dos alunos com autoria sobre suas aprendizagens.

Para que as propostas da professora gerassem práticas de letramento, houve uma série de condições. A primeira delas foi o laptop disponível diariamente na sala de aula, com o acesso à Internet. Outra condição foi o uso de um ambiente virtual onde se pudesse publicar/registrar/compartilhar as produções. Mais uma condição foi a proposta de trabalho por Projetos, uma orientação da formação do UCA, que criou o contexto e o sentido para que as outras atividades acontecessem. Além disso, o uso do Amadis a partir dos projetos criou o hábito de navegação no ambiente e gerou outros usos independentes da proposta da professora.

O laptop na modalidade 1:1 e o acesso a um ambiente virtual promoveram várias oportunidades de vivências de situações de uso com sentido da língua escrita, situações nas quais a língua escrita fazia parte dos mecanismos de interação e era demandada. Como a língua escrita fazia parte de um contexto, os sujeitos puderam participar e envolver-se em práticas sociais de letramento, sem mesmo dominar completamente o sistema alfabético. O uso do laptop e do ambiente virtual e a navegação na internet não foram limitados pelo não domínio do código. A necessidade de comunicar-se, de expressar-se através dos posts no diário, superou a barreira da língua escrita. Triangulando os dados e as análises dos dois eixos: Práticas de letramento propostas pela professora e Práticas de letramento espontâneas dos alunos, observamos em uma série cronológica que as primeiras tiveram uma grande influência sobre as segundas. Muitas das ações espontâneas dos alunos em relação ao uso da língua escrita foram influenciadas pelas propostas de sala de aula, mas principalmente pelas condições pedagógicas e tecnológicas oferecidas pelo projeto.

Para a emersão de uma cultura de letramento na escola é necessário uma ecologia de sistemas que a subsidie. O laptop é um elemento privilegiado mas não é suficiente. Para a cultura que se instalou na classe em que analisamos, além do equipamento também foram importantes a modalidade 1:1, a conexão com a internet, $\mathrm{o}$ uso de um ambiente virtual de comunicação e a autoria na rede. Em suma, para além do laptop, é necessário estabelecer uma ecologia de sistemas tecnológicos convergentes.

Em outras experiências não se vê o surgimento de um ambiente propício ao letramento como ocorreu na classe analisada. Em algumas delas, mesmo com o uso de ambiente virtuais e conexão com a internet, há falta de massa crítica de dispositivos computacionais para todos os alunos (1:1) para impactar na cultura de sala de aula. Em outras, abordadas por Kist (2010) há limitações de rede e ausência de ambiente virtual. 
$\mathrm{Na}$ experiência investigada tivemos uma convergência de fatores, ou seja, uma ecologia de sistemas computacionais associada a práticas pedagógicas diferenciadas, que possibilitaram o surgimento de um ambiente favorável ao letramento.

Mesmo considerando que no presente estudo a professora teve um papel chave em potencializar as experiências de aprendizagem acerca da língua escrita, ainda encontramos indícios nas práticas espontâneas dos alunos que suportam a conjectura implícita à proposta da OLPC, na qual o surgimento de uma cultura de aprendizagem com a tecnologia na escola poderia beneficiar os alunos, mesmo que o professor não se engaje totalmente no projeto ou apresente dificuldade com o uso da tecnologia. No entanto, adicionamos uma ressalva a essa conjectura, na qual apenas o dispositivo computacional (laptop/tablet) não é fator suficiente para formar a ecologia de sistemas tecnológicos que sustentaria tal cultura. A presença de outras tecnologias como o ambiente virtual e a internet têm papel fundamental na sustentação das práticas de letramento.

\section{Referências}

Bittencourt, J. (et. al). (2006) "Criando uma plataforma para Projetos de Aprendizagem: desafios e reflexões no desenvolvimento do AMADIS". In: RENOTE - Revista Eletrônica de Novas Tecnologias na Educação. Porto Alegre: s.ed., v.4, n.1, julho de 2006. Disponível em: http://www.cinted.ufrgs.br/renote/ Acesso em agosto de 2007.

Fagundes, L; (et. al) (1999) “Aprendizes do futuro: as inovações começaram!”. Brasília: MEC. 1999. http://mathematikos.psico.ufrgs.br/textos.html. Janeiro/2008.

Ferreiro, E. (et. al) (1999). "Psicogênese da Língua Escrita”. Porto Alegre: Artmed.

.; (2003) "Alfabetização e cultura escrita". In: Nova Escola. n.162. http://novaescola.abril.uol.com.br/ed/162_mai03/html/falamestre.htm. Maio/2003.

Kist, S. de O. (2009). "Um laptop por criança: implicações para as práticas de leitura e escrita”. Porto Alegre: UFRGS, Dissertação (Metrado em Educação). Programa de Pós-Graduação em Educação, Faculdade de Educação, Universidade Federal do Rio Grande do Sul, Porto Alegre.

.; (et. al) (2010) "Matsiko: Rwandan children doing curiosities investigation with their laptops". Constructionism 2010, Paris.

Maraschin, C. (1995) “O escrever na escola: da alfabetização ao letramento”. Porto Alegre: UFRGS, 1995. Tese (Doutorado em Educação). Programa de Pós-Graduação em Educação, Faculdade de Educação, Universidade Federal do Rio Grande do Sul, Porto Alegre.

Papert, S. (1994) “A máquina das crianças: repensando a escola na era da informática”. Porto Alegre: Artmed.

Soares, M. (2004) “Alfabetização e Letramento”. 3. ed. São Paulo: Contexto. Autêntica.

(2006) "Letramento: um tema em três gêneros". 2.ed. Belo Horizonte:

Yin, R. K. (2001) "Estudo de caso: planejamento e métodos”. Trad. Daniel Grassi - 2. ed . Porto Alegre: Bookman. 